\section{BRAZIULIAN JOURNAL}

OF MEDICAL AND BIOLOGICAL RLSH.ARCH

www.bjournal.com.br
ISSN 0100-879X

Volume 43 (02) 124-225 February 2010

BIOMEDICAL SCIENCES

AND

CLINICAL INVESTIGATION

Braz J Med Biol Res, February 2010, Volume 43(2) 160-165

Inflammatory response in a rat model of gastroschisis is associated with an increase of NF-kappaB

L. Sbragia, A.F. Schmidt, S. Moraes, D.G. Bittencourt, F.L.L. Gonçalves, L.A.V.D. Pereira and L.A. Velloso

The Brazilian Journal of Medical and Biological Research is partially financed by
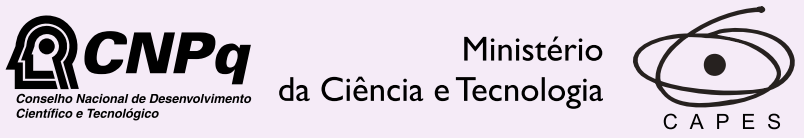

Ministério da Educação

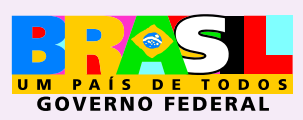

Institutional Sponsors 


\title{
Inflammatory response in a rat model of gastroschisis is associated with an increase of NF-kappaB
}

\author{
L. Sbragia ${ }^{1}$, A.F. Schmidt ${ }^{1}$, S. Moraes ${ }^{3}$, D.G. Bittencourt ${ }^{1}$, F.L.L. Gonçalves ${ }^{1}$, \\ L.A.V.D. Pereira ${ }^{3}$ and L.A. Velloso ${ }^{2}$ \\ 1Disciplina de Cirurgia Pediátrica, Departamento de Cirurgia, \\ 2Departamento de Clínica Médica, Faculdade de Ciências Médicas, and \\ ${ }^{3}$ Departamento de Histologia e Embriologia, Instituto de Biologia, \\ Universidade Estadual de Campinas, Campinas, SP, Brasil
}

\begin{abstract}
Babies with gastroschisis have high morbidity, which is associated with inflammatory bowel injury caused by exposure to amniotic fluid. The objective of this study was to identify components of the inflammatory response in the intestine and liver in an experimental model of gastroschisis in rats. The model was surgically created at 18.5 days of gestation. The fetuses were exposed through a hysterotomy and an incision at the right of the umbilicus was made, exposing the fetal bowel. Then, the fetus was placed back into the uterus until term. The bowel in this model had macro- and microscopic characteristics similar to those observed in gastroschisis. The study was conducted on three groups of 20 fetuses each: gastroschisis, control, and sham fetuses. Fetal body, intestine and liver weights and intestine length were measured. IL-1 $\beta$, IL-6, IL-10, TNF- $\alpha$, IFN- $\gamma$ and NF-kappaB levels were assessed by ELISA. Data were analyzed statistically by ANOVA followed by the Tukey post-test. Gastroschisis fetuses had a decreased intestine length (means $\pm S D, 125 \pm 25$ vs $216 \pm 13.9$; $P<0.005$ ) and increased intestine weight $(0.29 \pm 0.05$ vs $0.24 \pm 0.04 ; P<0.005)$. Intestine length correlated with liver weight only in gastroschisis fetuses (Pearson's correlation coefficient, $r=0.518, P=0.019$ ). There were no significant differences in the concentrations of IL-1 $\beta$, TNF- $\alpha$ or IFN-y in the intestine, whereas the concentration of NF-kappaB was increased in both the intestine and liver of fetuses with gastroschisis. These results show that the inflammatory response in the liver and intestine of the rat model of gastroschisis is accompanied by an increase in the amount of NF-kappaB in the intestine and liver.
\end{abstract}

Key words: Gastroschisis; Inflammation; Inflammatory mediators; Nuclear factor kappaB

\section{Introduction}

Gastroschisis affects $1.62 / 10,000$ liveborns (1) and this incidence is increasing worldwide (2). Despite a low mortality, these patients have a high morbidity rate associated with dysmotility, intestinal atresia and necrotizing enterocolitis (3). These anatomical and functional changes have been attributed to the exposure of the intestine to amniotic fluid (4). The intestine presents loss of contractility, decreased enzymatic activity of the villi and alterations in collagen synthesis in the submucosal region (5). These histological $(6,7)$ and biochemical $(8,9)$ abnormalities resulting from inflammation have been demonstrated in both experimental models and humans.

Investigation of human amniotic fluid in gastroschisis has shown increased cellularity and increased levels of total pro- tein, ferritin, interleukin (IL)-6, and IL-8 (10). However, the specific inflammatory pathways that are activated in the chronic inflammation of the intestine observed in gastroschisis are not known. Among the proinflammatory cytokines involved in intestinal lesions are tumor necrosis factor- $\alpha$ (TNF- $\alpha)$, IL-6 and interferon-gamma (IFN- $\gamma$ ) (11). All of these factors may be stimulated by the activation of hepatic NF-kappa. When the cells are stimulated, NF-kappaB is released and migrates to the nucleus, where it interacts with a specific sequence in the region that promotes target genes (12).

The hepatic Kupffer cells (hepatic histiocytes) are the cells that produce NF-kappaB the most, followed by the hepatocytes themselves (12). The regulation of inflammation and necrosis involves an intricate balance between pro- and

Correspondence: L. Sbragia, Disciplina de Cirurgia Pediátrica, Departamento de Cirurgia, FCM, UNICAMP, Rua Alexander Fleming, 40, 13084-970 Campinas, SP, Brasil. Fax: +55-19-3521-9450. E-mail: sbragia@fmrp.usp.br

Received August 20, 2009. Accepted December 17, 2009. Available online January 22, 2010. Published February 1, 2010. 
anti-inflammatory cytokines. Among the genes activated by NF-kappaB are proinflammatory genes and codifiers of cytotoxic cytokines (13). NF-kappaB also participates in the prevention of apoptosis during hepatic regeneration (14).

We hypothesized that the intestinal inflammatory process triggered by the amniotic fluid in gastroschisis may be sufficient to activate specific pathways of the inflammatory response not only in the intestine, but also in the liver. For this purpose, we assessed the levels of cytokines in the liver and intestine in an experimental rat model of gastroschisis.

\section{Material and Methods}

The experimental protocol was approved by the Animal Research Committee of the University of Campinas (UNICAMP) and followed the Guidelines for the Care and Use of Laboratory Animals (internal \#281-1).

\section{Model}

Female Sprague-Dawley rats were mated and checked for introital plugging. The day of plugging was defined as gestational day 0 for time dating (term $=22$ days). The pregnant rats were kept in individual cages and acclimated to dark/light cycling conditions.

On day 18.5 of gestation, the animals underwent surgery in order to create experimental gastroschisis. The procedure was performed under anesthesia with ketamine $(50 \mathrm{mg} / \mathrm{mL}$; Pfizer do Brasil Ltda., Brazil) in combination with xylazine (10 mg/mL; Rompun ${ }^{\circledR}$, Bayer do Brasil Ltda., Brazil) administered in the right posterior limb. The abdominal ventral region was shaven with an electric razor (Sunbeam ${ }^{\circledR}$, USA) and cleaned with chlorohexidine soap. The abdominal wall was opened through a median longitudinal incision and the uterus was exposed. Fetuses were operated upon according to the technique of Correia-Pinto et al. (15). For creation of gastroschisis, a purse-string suture was placed in the uterine wall near the lower body of the fetus. The uterus and the amniotic cavity was then opened and the lower body of the fetus was carefully exposed through the incision. A 3-mm incision was then made on the abdominal wall of the fetus to the right of the umbilicus, through which the fetal bowel was exposed. We modified the technique of Correia-Pinto et al. (15) with a maneuver that facilitated the abdominal opening procedure. We exposed both legs of the fetus and made the incision with a direct view of the umbilical cord. This position permitted a very safe and controlled incision without damage to the umbilical vasculature. After exposure of the fetal bowel, the lower body of the fetus was carefully placed back into the amniotic cavity and the uterus and the purse-string suture of the uterine wall was closed. The first and last fetuses in each uterine horn were not used. The remaining fetuses were then sequentially used as follows: the second fetus, the first to be operated upon, was the fetus with gastroschisis, the subsequent one was the control fetus, the next one was the sham fetus, and so on. Control fetuses were left undisturbed and sham fetuses were exposed to hysterectomy and manipulated but without abdominal wall opening. After gastroschisis and sham operations were made in both uterine horns, the uterus was placed back in the abdominal cavity of the mother and the abdominal wall was closed in two layers. A total of 24 fetuses were included in each group - gastroschisis, control and sham.

Fetuses were harvested by cesarean section on day 21.5 of gestation. Fetuses were weighed and then sacrificed with a lethal dose of anesthetic. The intestinal tract was removed from pylorus to rectum and its length was measured.

The three groups of fetuses were compared for body weight (BW), liver weight (LW), intestine weight (IW), intestine length (IL), liver weight/body weight ratio (LW/BW), intestine weight/body weight ratio (IW/BW) and intestine weight/intestine length ratio (IW/IL).

\section{Immunoprecipitation}

Liver and intestine fragments were homogenized in immunoprecipitation buffer containing $1 \%$ Triton X-100, $100 \mathrm{mM}$ Tris, $\mathrm{pH} 7.4,100 \mathrm{mM}$ sodium pyrophosphate, 100 $\mathrm{mM}$ sodium fluoride, $10 \mathrm{mM}$ EDTA, $10 \mathrm{mM}$ sodium orthovanadate, $2 \mathrm{mM} \mathrm{PMSF}$, and $0.1 \mathrm{mg} / \mathrm{mL}$ aprotinin at $4^{\circ} \mathrm{C}$. The homogenized sample was then centrifuged at 11,000 rpm for $20 \mathrm{~min}$. Supernatant protein concentration was measured by the method of Lowry and immunoprecipitation was achieved with a specific anti-NF-kappaB antibody in a 1:10,000 dilution according to manufacturer instructions (Pierce Biotechnology, USA). Following incubation, immunocomplexes were recovered with Protein A Sepharose 6 $\mathrm{MB}$ for $2 \mathrm{~h}$ at $4^{\circ} \mathrm{C}$ and decanted by centrifugation for 20 $\min$ at $4^{\circ} \mathrm{C} / 11,000 \mathrm{rpm}$. The precipitate was washed three times at 5-min intervals, with a washing buffer ( $2 \mathrm{mM}$ sodium orthovanadate, $100 \mathrm{mM}$ Tris- $\mathrm{HCl}, 1 \mathrm{mM}$ RDTA, and 0.5\% Triton X-100). The supernatant was discarded and only the precipitated proteins (immunocomplexes) were retained.

\section{ELISA for cytokine determination}

Tissue levels of IL-1 $\beta$, TNF- $\alpha$, IL- 6 , and IFN- $\gamma$ were determined in total protein extracts of liver and intestine $(2.0 \mathrm{mg} /$ $\mathrm{mL}$ ) using $25 \mu \mathrm{g}$ total protein by ELISA (Pierce Biotechnology, USA) following manufacturer recommendations.

\section{Determination of NF-kappaB activation}

Liver and intestine NF-kappaB activation was determined in nuclear extracts by ELISA (Pierce Biotechnology, USA) according to manufacturer recommendations and using the positive and negative controls supplied.

\section{Immunohistochemical procedures}

Immunohistochemistry was performed using liver specimens from four fetuses. Six-micrometer cryostat sections were prepared from frozen liver, transferred to slides coated with poly-L-lysine and fixed in methanol for $10 \mathrm{~min}$. 
The sections were washed twice in $0.01 \mathrm{M}$ phosphatebuffered saline (PBS), $\mathrm{pH} 7.4$, and endogenous peroxidase was eliminated by exposure to $0.03 \%$ hydrogen peroxide $(\mathrm{v} / \mathrm{v})$ in methanol for $5 \mathrm{~min}$ at room temperature. Sections were washed in PBS followed by incubation in PBS with $1 \%$ bovine serum albumin (BSA, w/v) for 30 min to block nonspecific background. Upon BSA removal, the sections were treated with mouse anti-rat CD68 (ED1) and CD163 (ED2; Serotec, USA) at a 1:50 dilution in PBS/BSA overnight at $4^{\circ} \mathrm{C}$. After washing in PBS, slides were covered with a 1:200 dilution of biotinylated horse anti-mouse IgG (Vector Laboratories, USA) in PBS, as the second antibody for 45 $\mathrm{min}$. The sections were subsequently washed in PBS and incubated for 30 min with streptoABC complex/HRP (Dako, Denmark) prepared according to manufacturer instructions. After washing in $10 \mathrm{mM}$ Tris-buffered saline (TBS), $\mathrm{pH} 7.6$, the antigen was visualized in tissue by staining for peroxidase activity with 3,3'-diaminobenzidine-tetra-hydrochloride (DAB, Sigma, USA) in TBS, $\mathrm{pH} 7.6$, containing $\mathrm{H}_{2} \mathrm{O}_{2}$, and rinsing in distilled water. The sections were lightly counterstained with Ehrlich's hematoxylin, rinsed in distilled water, dehydrated, and mounted with a permanent mounting medium. Negative immunohistochemistry controls were treated in the same way, omitting the primary antibody. After staining, the slides were examined by two different pathologists who counted the number of ED1 and ED2 hepatic cells.

\section{Statistical analysis}

Data are reported as means \pm SD and were analyzed statistically by ANOVA using the Statistical Analysis System for Windows (SAS 8.01, SAS Institute Corporation 1999-2000, USA), with the level of significance set at $5 \%(P<0.05)$.

\section{Results}

\section{Morphometric evaluation of liver and intestine}

The intestine and liver measurements are presented in Table 1. The liver of control fetuses was lighter compared to gastroschisis fetuses and the LW/ BW relationship was lower in control fetuses compared to both gastroschisis and sham fetuses. The intestine was heavier and shorter in gastroschisis compared to control and sham fetuses and the IW/IL and IW/ BW ratios were higher in gastroschisis fetuses $(P<$ 0.05).

We then correlated $\mathrm{IL}$ and $\mathrm{LW}$ in the various groups using the Pearson's correlation coefficient ( $r=$ Pearson's coefficient), with the following results: gastroschisis $(r=0.518, P=0.019)$, control $(r=0.071, P$ $=0.766)$ and $\operatorname{sham}(r=0.017, P=0.942)$. This shows that there is a statistical relationship between intestine length and liver weight in gastroschisis but not in control or sham fetuses (Figure 1). For the gastroschisis group, the linear least squares regression model was adjusted for analysis and the following estimated equation of intestine length based on liver weight was obtained: intestine length $=57.53+195.22 x$ liver weight $\left(R^{2}=26.8 \% ; S_{x y}=23.86\right.$; $C V=19.1 \% ; P=0.0193)$ (Figure 1).

\section{Determination of cytokine expression in liver and intestine}

There were decreased levels of IL-1 $\beta$ and TNF- $\alpha$ in the liver of gastroschisis fetuses. No significant differences in the amounts of IL-1 $\beta$, TNF- $\alpha$, IL-6, or IFN- $\gamma$ were found in the intestine (Table 2).

Determination of NF-kappaB concentration in liver and intestine. There was a 4-and 2-fold increase in NF-kappaB concentration in the liver and intestine, respectively (Table 3).

Determination of macrophage activation in the liver. Since an increase in NF-kappaB was detected in the liver, we investigated the presence of activated macrophages in this tissue with an immunohistochemical assay using

Table 1. Morphometric data for a rat model of gastroschisis.

\begin{tabular}{lccc}
\hline & Gastroschisis & Control & Sham \\
\hline Body weight (BW, g) & $5.29 \pm 0.69^{*}$ & $5.67 \pm 0.56$ & $5.87 \pm 0.49$ \\
Liver weight (LW, g) & $0.36 \pm 0.07$ & $0.33 \pm 0.04^{+}$ & $0.38 \pm 0.06$ \\
Intestine weight (IW, g) & $0.29 \pm 0.05^{\star \#}$ & $0.24 \pm 0.04$ & $0.23 \pm 0.034$ \\
Intestine length (IL, mm) & $125 \pm 25.0^{\star \#}$ & $216 \pm 13.9$ & $209 \pm 15.9$ \\
LW/BW (\%) & $6.7 \pm 0.1^{\#}$ & $5.8 \pm 0.7^{+}$ & $6.3 \pm 0.9$ \\
IW/BW (\%) & $5.5 \pm 1.0^{\star \#}$ & $4.1 \pm 0.6$ & $4.0 \pm 0.8$ \\
IW/L (mg/mm) & $2.42 \pm 0.46^{\star \#}$ & $1.09 \pm 0.19$ & $1.11 \pm 0.24$ \\
\hline
\end{tabular}

Data are reported as means $\pm S D$ for 24 rats in each group. ${ }^{*} P<0.05$, gastroschisis vs sham; ' $\mathrm{P}<0.05$, control vs sham; ${ }^{\mathrm{P}}<0.05$, gastroschisis vs control (ANOVA with the Tukey-Kramer post-test).

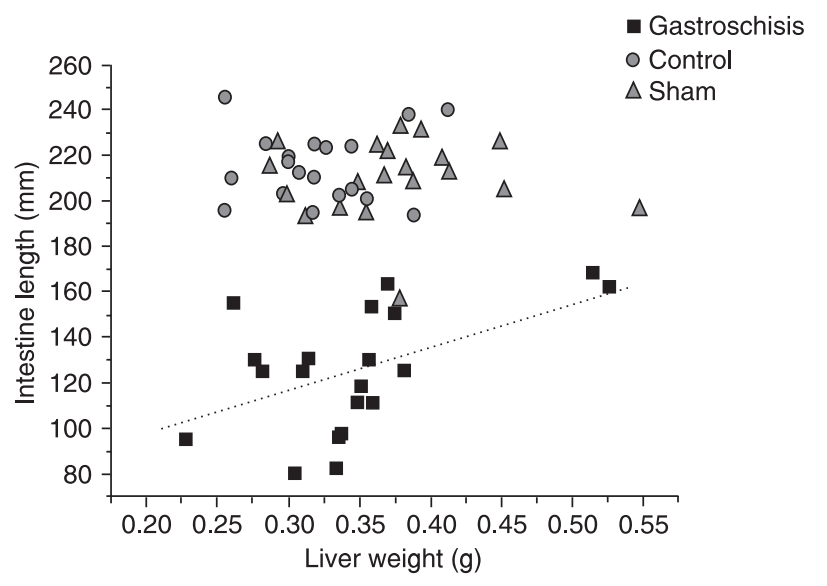

Figure 1. Correlation between liver weight and intestinal length at 18.5 days of gestation in rats with gastroschisis. 
Table 2. IL, TNF- $\alpha$ and IFN- $y$ levels in the intestine of a rat model of gastroschisis.

\begin{tabular}{lccc}
\hline & Gastroschisis & Control & Sham \\
\hline IL-1 $\beta$ & $49 \pm 4.0$ & $71.5 \pm 27.1$ & $52.2 \pm 13$ \\
IL-6 & $166.5 \pm 1.1$ & $190.5 \pm 10.7$ & $186.8 \pm 15.9$ \\
IL-10 & $28 \pm 5.2$ & $24.6 \pm 1.3$ & $28.8 \pm 0.3$ \\
TNF- $\alpha$ & $0.11 \pm 0.04$ & $0.19 \pm 0.03$ & $0.16 \pm 0.04$ \\
IFN- $\gamma$ & $5.6 \pm 0.9$ & $7.9 \pm 2.0$ & $5.6 \pm 1.5$ \\
\hline
\end{tabular}

Data are reported as means $\pm \mathrm{SD}$ in $\mathrm{pg} / 2 \mathrm{mg}$ intestine homogenate protein for 4 rats in each group. There were no statistical differences among groups (ANOVA with the Tukey post-test).

Table 3. Levels of NF-kappaB in the liver and intestine of a rat model of gastroschisis.

\begin{tabular}{lccc}
\hline & Gastroschisis & Control & Sham \\
\hline Liver $(\mathrm{g})$ & $0.105 \pm 0.03^{*+}$ & $0.025 \pm 0.018$ & $0.021 \pm 0.033$ \\
Intestine $(\mathrm{g})$ & $0.021 \pm 0.002^{*+}$ & $0.014 \pm 0.006$ & $0.013 \pm 0.009$ \\
\hline
\end{tabular}

Data are reported as means \pm SD in $\mathrm{pg} / 2 \mathrm{mg}$ liver homogenate protein for 5 rats in each group. ${ }^{*} P<0.05$, gastroschisis vs control; ${ }^{+} \mathrm{P}<0.05$, gastroschisis vs sham (ANOVA with the Tukeypost-test).

anti-ED1 and anti-ED2 antibodies. The average number of cells stained for ED1 was $18 \pm 5$ in gastroschisis, $16 \pm$ 6 in control and $19 \pm 9$ in sham fetuses. The numbers of cells stained for ED2 were $16 \pm 3$ in gastroschisis, $16 \pm 7$ in control and $12 \pm 3$ in sham fetuses. There were no significant differences among groups. Therefore, although we observed an increase in NF-kappaB in the liver of fetuses with gastroschisis this increase was not able to activate macrophages.

\section{Discussion}

The survival rate of neonates with gastroschisis has increased in the last decades. Intestinal damage is still responsible for the increased morbidity and eventual mortality of these patients. The factors that contribute to morbidity and mortality include prematurity, low birth weight and gastrointestinal complications such as atresia, stenosis, necrotizing enterocolitis, and intestinal hypomotility derived from prolonged exposure of the intestine to components of the amniotic fluid $(16,17)$.

The inflammatory process in gastroschisis starts in the uterus. Macroscopically, the exposed intestine is found to be thickened, shortened and coated with a fibrin layer $(4,18,19)$. The intestine presents functional alterations such as loss of contractility, decreased enzymatic activity of the villi, and changes in collagen synthesis in the submucosal region (5). There are also alterations in the distal mesenteric vascular system (vasa recta), with a larger number and density of these small vessels.

We observed that the intestine of gastroschisis fetuses had an increased weight and decreased length, probably due to the intestinal edema resulting from exposure to amniotic fluid. Consequently, the IW/IL and IW/BW ratios were also significantly increased in gastroschisis.

On the other hand, in the experimental model of rat fetuses with intrauterine growth restriction, the liver weight is decreased (20). We have previously demonstrated intrauterine growth restriction in gastroschisis fetuses (21) but we did not correlate it with liver weight. In the present study, we observed that control fetuses were heavier than gastroschisis fetuses, but there was no difference between sham fetuses and gastroschisis or control fetuses. In addition, although the liver is proportionally larger in gastroschisis fetuses when adjusted to body weight (LW/BW), this difference was detected between gastroschisis versus controls $(P<0.05)$, but not between gastroschisis versus sham fetuses. This might be due to the fact that just the surgical stress of opening the amniotic cavity and manipulating the fetus without exposing their bowel to the amniotic cavity can affect the LW/BW ratio, so that the difference observed in gastroschisis fetuses might be attributed to surgical stress and not to gastroschisis.

Of particular interest is the finding that the correlation between liver weight and intestinal length was only observed in gastroschisis. We may speculate that perhaps, since inflammation shortens the intestine, the degree of the inflammatory response might be inversely related to intestinal length and thus, the greater the inflammatory response, the shorter the intestine and the lighter the liver.

To assess the degree of inflammatory reaction we investigated cytokine levels. Proinflammatory cytokines such as TNF- $\alpha$ and IL-1 are the main stimuli for the secretion of chemokines such as IL-6 and are detected during the acute phase of inflammation. Later, IL-6 down-regulates the production of TNF- $\alpha$ and IL-1 (22). During the gestation of human fetuses with gastroschisis a subchronic pattern of interleukins has been reported in the amniotic fluid with an increase of IL-6 and IL-8 (10). In the present study, the perinatal levels of TNF- $\alpha$ and IFN- $\gamma$ were normal in the intestine and there was a decrease of TNF- $\alpha$ and IL-1 $\beta$ in the liver of the fetuses with gastroschisis. This decrease could be due to a later stage of the inflammatory process during the perinatal period.

Intestinal inflammation has also been associated with the increase of NF-kappaB, which has been demonstrated to play a key role both in inflammatory bowel disease and gastroschisis (23-26). We also found elevation of NFkappaB levels both in the intestine and liver of fetuses with gastroschisis $(P<0.05)$. These results show that there was activation of the inflammatory cascade both in the intestine 
and in the liver, suggesting that the inflammatory response in gastroschisis is activated in both organs.

The increase of NF-kappaB has been associated with an increased number of circulating and tissue histiocytes (ED1 and ED2) (13). However, in the gastroschisis model, we did not observe this phenomenon. Although the inflammation of the intestine might have been sufficient to increase NF-kappaB levels in both the intestine and the liver, it might not have been strong enough to increase the number of histiocytes, due to the lack of infectious stimuli of inflammation.

Finally, we observed that the inflammatory cascade activation expressed by an increase of NF-kB levels exists in the intestine and mainly in the liver of rats with experimental gastroschisis represented by an observed decrease of IL-1 $\beta$ and TNF- $\alpha$. These data support the theory that the intestine-liver axis has a role in the inflammatory process

\section{References}

1. Loane M, Dolk H, Bradbury I. Increasing prevalence of gastroschisis in Europe 1980-2002: a phenomenon restricted to younger mothers? Paediatr Perinat Epidemiol 2007; 21: 363-369.

2. Suita S, Okamatsu T, Yamamoto T, Handa N, Nirasawa $Y$, Watanabe $\mathrm{Y}$, et al. Changing profile of abdominal wall defects in Japan: results of a national survey. $J$ Pediatr Surg 2000; 35: 66-71.

3. Eggink BH, Richardson CJ, Malloy MH, Angel CA. Outcome of gastroschisis: a 20-year case review of infants with gastroschisis born in Galveston, Texas. J Pediatr Surg 2006; 41: 1103-1108.

4. Langer JC, Longaker MT, Crombleholme TM, Bond SJ, Finkbeiner WE, Rudolph CA, et al. Etiology of intestinal damage in gastroschisis. I: Effects of amniotic fluid exposure and bowel constriction in a fetal lamb model. $J$ Pediatr Surg 1989; 24: 992-997.

5. Srinathan SK, Langer JC, Blennerhassett MG, Harrison MR, Pelletier GJ, Lagunoff D. Etiology of intestinal damage in gastroschisis. III: Morphometric analysis of the smooth muscle and submucosa. J Pediatr Surg 1995; 30: 379-383.

6. Tibboel D, Vermey-Keers C, Kluck P, Gaillard JL, Koppenberg J, Molenaar JC. The natural history of gastroschisis during fetal life: development of the fibrous coating on the bowel loops. Teratology 1986; 33: 267-272.

7. Amoury RA, Beatty EC, Wood WG, Holder TM, Ashcraft KW, Sharp RJ, et al. Histology of the intestine in human gastroschisis - relationship to intestinal malfunction: dissolution of the "peel" and its ultrastructural characteristics. $J$ Pediatr Surg 1988; 23: 950-956.

8. Saleh AA, Isada NB, Johnson MP, Sokol RJ, Dombrowski MP, Evans MI. Amniotic fluid acetylcholinesterase is found in gastroschisis but not omphalocele. Fetal Diagn Ther 1993; 8: 168-170.

9. Bealer JF, Graf J, Bruch SW, Adzick NS, Harrison MR. Gastroschisis increases small bowel nitric oxide synthase activity. J Pediatr Surg 1996; 31: 1043-1045.

10. Guibourdenche J, Berrebi D, Vuillard E, de Lagausie P, Ai- of experimental gastroschisis. Moreover, shorter bowel loops accompany smaller livers. The implications of the hepatic inflammatory process activated in gastroschisis may stimulate new studies of the prognosis and treatment of fetal gastroschisis, as well as studies of responses to the fetal insulin receptors in the presence of in utero inflammatory processes and growth retardation in gastroschisis $(27,28)$.

To our knowledge, this is the first study demonstrating activation of the inflammatory response in the liver of the rat model of gastroschisis. Further investigations are needed to elucidate other inflammatory pathways involved and their consequences.

\section{Acknowledgments}

Research supported by FAPESP (\#02/02563-8). grain Y, Oury JF, et al. Biochemical investigations of bowel inflammation in gastroschisis. Pediatr Res 2006; 60: 565568.

11. Nanji AA, Jokelainen $K$, Rahemtulla A, Miao L, Fogt F, Matsumoto $\mathrm{H}$, et al. Activation of nuclear factor kappa $B$ and cytokine imbalance in experimental alcoholic liver disease in the rat. Hepatology 1999; 30: 934-943.

12. Baeuerle PA, Baltimore D. NF-kappa B: ten years after. Cell 1996; 87: 13-20.

13. Barnes PJ, Karin M. Nuclear factor-kappaB: a pivotal transcription factor in chronic inflammatory diseases. N Engl J Med 1997; 336: 1066-1071.

14. limuro $Y$, Nishiura T, Hellerbrand C, Behrns KE, Schoonhoven R, Grisham JW, et al. NFkappaB prevents apoptosis and liver dysfunction during liver regeneration. J Clin Invest 1998; 101: 802-811.

15. Correia-Pinto J, Tavares ML, Baptista MJ, Estevao-Costa J, Flake AW, Leite-Moreira AF. A new fetal rat model of gastroschisis: development and early characterization. J Pediatr Surg 2001; 36: 213-216.

16. Snyder CL. Outcome analysis for gastroschisis. J Pediatr Surg 1999; 34: 1253-1256.

17. Driver CP, Bruce J, Bianchi A, Doig CM, Dickson AP, Bowen $J$. The contemporary outcome of gastroschisis. J Pediatr Surg 2000; 35: 1719-1723.

18. Oldham KT, Coran AG, Drongowski RA, Baker PJ, Wesley JR, Polley TZ Jr. The development of necrotizing enterocolitis following repair of gastroschisis: a surprisingly high incidence. J Pediatr Surg 1988; 23: 945-949.

19. Dilsiz A, Gundogan AH, Aktan M, Duman S, Aktug T. Nitric oxide synthase inhibition prevents intestinal damage in gastroschisis: a morphological evaluation in chick embryos. J Pediatr Surg 1999; 34: 1248-1252.

20. Wigglesworth JS. Experimental growth retardation in the foetal rat. J Pathol Bacteriol 1964; 88: 1-13.

21. Franchi-Teixeira AR, Weber Guimaraes BM, Nogueira B, Bittencourt D, Violin L, Sbragia L. Aminiotic fluid and intrauterine growth restriction in a gastroschisis fetal rat model. 
Fetal Diagn Ther 2005; 20: 494-497.

22. Luster AD. Chemokines - chemotactic cytokines that mediate inflammation. N Engl J Med 1998; 338: 436-445.

23. Atreya I, Atreya R, Neurath MF. NF-kappaB in inflammatory bowel disease. J Intern Med 2008; 263: 591-596.

24. Halpern MD, Khailova L, Molla-Hosseini D, Arganbright K, Reynolds C, Yajima M, et al. Decreased development of necrotizing enterocolitis in IL-18-deficient mice. Am J Physiol Gastrointest Liver Physiol 2008; 294: G20-G26.

25. De Plaen IG, Liu SX, Tian R, Neequaye I, May MJ, Han XB, et al. Inhibition of nuclear factor-kappaB ameliorates bowel injury and prolongs survival in a neonatal rat model of necrotizing enterocolitis. Pediatr Res 2007; 61: 716-721.
26. Halpern MD, Holubec H, Dominguez JA, Meza YG, Williams CS, Ruth MC, et al. Hepatic inflammatory mediators contribute to intestinal damage in necrotizing enterocolitis. $A m ~ J$ Physiol Gastrointest Liver Physiol 2003; 284: G695-G702.

27. Bolke E, Jehle PM, Trautmann M, Gotz I, Krebs B, Steinbach $G$, et al. Different acute-phase response in newborns and infants undergoing surgery. Pediatr Res 2002; 51: 333-338.

28. Denley A, Bonython ER, Booker GW, Cosgrove LJ, Forbes $\mathrm{BE}$, Ward CW, et al. Structural determinants for high-affinity binding of insulin-like growth factor II to insulin receptor (IR)A, the exon 11 minus isoform of the IR. Mol Endocrinol 2004; 18: $2502-2512$. 